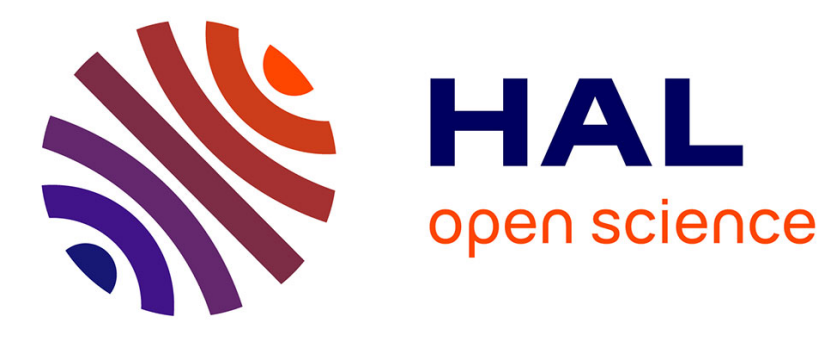

\title{
Trapping heavy metals by using calcium hydroxyapatite and dielectrophoresis
}

\author{
John Batton, Arun John Kadaksham, Ange Nzihou, Pushpendra Singh, \\ Nadine Aubry
}

\section{- To cite this version:}

John Batton, Arun John Kadaksham, Ange Nzihou, Pushpendra Singh, Nadine Aubry. Trapping heavy metals by using calcium hydroxyapatite and dielectrophoresis. Journal of Hazardous Materials, 2007, First International Conference on Engineering for Waste Treatment: Beneficial Use of Waste and By-Products (WasteEng2005), 139 (3), pp.461-466. 10.1016/j.jhazmat.2006.02.057 . hal-01634393

\section{HAL Id: hal-01634393 \\ https://hal.science/hal-01634393}

Submitted on 22 Oct 2020

HAL is a multi-disciplinary open access archive for the deposit and dissemination of scientific research documents, whether they are published or not. The documents may come from teaching and research institutions in France or abroad, or from public or private research centers.
L'archive ouverte pluridisciplinaire HAL, est destinée au dépôt et à la diffusion de documents scientifiques de niveau recherche, publiés ou non, émanant des établissements d'enseignement et de recherche français ou étrangers, des laboratoires publics ou privés. 


\title{
Trapping heavy metals by using calcium hydroxyapatite and dielectrophoresis
}

\author{
John Batton ${ }^{\mathrm{a}}$, Arun John Kadaksham ${ }^{\mathrm{a}}$, Ange Nzihou ${ }^{\mathrm{b}}$, Pushpendra Singh ${ }^{\mathrm{a}}$, Nadine Aubry ${ }^{\mathrm{a}, *}$ \\ a Department of Mechanical Engineering and New Jersey Center for Micro-Flow Control, \\ New Jersey Institute of Technology, Newark, NJ 07102, United States \\ ${ }^{\mathrm{b}}$ Ecole des Mines d'Albi-Carmaux, LGPSD, UMR CNRS 2392, Route de Teillet, 81013 ALBI CT Cedex 09, France
}

\begin{abstract}
We propose a novel technique for the removal of heavy metal waste from contaminated water. Our method consists in using dielectrophoresis (DEP) to trap hydroxyapatite (HAP) particles of $1 \mu \mathrm{m}$ size in water after they have adsorbed heavy metal ( $\mathrm{Pb}, \mathrm{Zn}, \mathrm{Cu}, \mathrm{Co}$ and $\mathrm{Cr}$ ). Although $\mathrm{HAP}$ can adsorb heavy metals in water and as such offers great promise as a waste-cleaning tool [1-3], one of the current challenges is the efficient removal of the HAP particles once they have adsorbed the heavy metals. We show in this paper that DEP can be used to concentrate such particles in certain regions, thus rendering the rest of the solution volume nearly free of contaminated particles. We present here both experimental and numerical results for suspensions at low concentrations.
\end{abstract}

Keywords: Dielectrophoresis (DEP); Calcium hydroxyapatite (HAP); Waste water filtration; Removal of heavy metals; MEMS; Microfluidics

\section{Introduction}

The presence of toxic compounds in water from agricultural, industrial and household origins has become an environmental issue leading, for instance, to loss of biological diversity in contaminated rivers. In this paper, we focus on the removal of heavy metals such as $\mathrm{Pb}, \mathrm{Cu}, \mathrm{Zn}, \mathrm{Co}$ and $\mathrm{Cr}$ from contaminated water. While it is well-established that hydroxyapatite (HAP) particles can adsorb heavy metals in water, the application of the method as a decontamination technique has been limited due to the difficulty of removing particles once the adsorption process is complete. The present work uses micrometer-sized HAP particles to adsorb heavy metals from contaminated water and then dielectrophoresis as a means of manipulating and concentrating the HAP particles in specific locations from where they can be easily removed.

Dielectrophoresis is the controlled motion of uncharged polarizable particles in a non-uniform electric field. In a spatially non-uniform ac electric field, dielectric particles experience a translational force as a consequence of the interaction

\footnotetext{
* Corresponding author. Tel.: +1 973596 3314; fax: +1 9736424282 .

E-mail addresses: Ange.Nzihou@enstimac.fr(A. Nzihou),singhp@ njit.edu (P. Singh), aubry@njit.edu (N. Aubry).
}

of the polarization of the particle induced by the electric field with the non-uniformity in that field. The resulting particle movement was termed dielectrophoresis (DEP) by Pohl [4]. Dielectrophoresis is a powerful tool for the manipulation of a broad range of particles, including micro- and nanosized particles [5-9]. It is well-known that when particles are suspended in a liquid chamber subjected to a non-uniform electric field, the particle distribution becomes non-uniform and the particles agglomerate either near or away from the electrodes, depending on the sign of the real part of the frequency-dependent Clausius-Mossotti factor given by

$\beta(\omega)=\left(\frac{\varepsilon_{\mathrm{p}}^{*}-\varepsilon_{\mathrm{c}}^{*}}{\varepsilon_{\mathrm{p}}^{*}+2 \varepsilon_{\mathrm{c}}^{*}}\right)$

where $\varepsilon_{\mathrm{c}}^{*}$ and $\varepsilon_{\mathrm{p}}^{*}$ are the complex permittivities of the liquid and of the particles, respectively. This property can be used for concentrating and then removing undesirable particles from liquids.

In a spatially varying ac electric field, the time averaged dielectrophoretic force acting on an isolated particle is often modeled by the point dipole approximation, which reads

$$
F_{\text {DEP }}=4 \pi a^{3} \varepsilon_{0} \varepsilon_{\mathrm{c}} \operatorname{Re}(\beta(\omega)) \mathbf{E} \cdot \nabla \mathbf{E},
$$

where $a$ is the particle radius, $\varepsilon_{0}$ the dielectric constant of the vacuum and $\mathbf{E}$ is the RMS value of the electric field. Expression 
(1) can also be used in the case of a dc electric field in which case $\mathbf{E}$ represents the electric field.

From this expression it is clear that when $\operatorname{Re}(\beta)$ is positive the direction of the dielectrophoretic force is along the gradient of the magnitude of the electric field and when $\operatorname{Re}(\beta)$ is negative the force acts in the opposite direction. It follows that when $\operatorname{Re}(\beta)$ is positive, the dielectrophoretic force moves the particles into the regions where the electric field strength is locally maximum which is normally on the electrode surfaces (positive dielectrophoresis). On the other hand, when $\operatorname{Re}(\beta)$ is negative the particles move into the regions where the electric field strength is locally minimum (negative dielectrophoresis).

\section{Numerical simulations}

\subsection{Numerical scheme and governing equation}

We now proceed with the numerical simulation of the system and then describe the results obtained from these simulations. We use direct numerical simulation (DNS) where the equations for the fluid and the particles are solved without any assumption or modeling. It is performed using a numerical technique based on the distributed Lagrange multiplier method [10], where the fluid flow equations are solved on the combined fluid-solid domain, and the motion inside the particle boundaries is forced to be rigid-body motion using a distribution of Lagrange multipliers. The suspending fluid is assumed to be Newtonian and non-conducting, and the particles spherical and monodispersed.

Let $\Omega$ be the domain containing a Newtonian fluid and $N$ solid spherical particles, $P_{i}(t)$ the interior of the $i$ th particle and $\Gamma$ the domain boundary. The governing equations for the fluid-particle system are

$\rho_{\mathrm{L}}\left(\frac{\partial \mathbf{u}}{\partial t}+\mathbf{u} \cdot \nabla \mathbf{u}\right)=-\nabla p+\nabla \cdot(2 \eta \mathbf{D}) \quad$ in $\Omega \backslash \overline{P(t)}$

$\nabla \cdot \mathbf{u}=0 \quad$ in $\Omega \backslash \overline{P(t)}$

$\mathbf{u}=\mathbf{u}_{\mathrm{L}} \quad$ on $\Gamma$

$\mathbf{u}=\mathbf{U}_{i}+\boldsymbol{\omega}_{i} \times \mathbf{r}_{i} \quad$ on $\partial P_{i}(t), i=1, \ldots, N$

Here, $\mathbf{u}$ is the fluid velocity, $p$ the pressure, $\eta$ the dynamic viscosity of the fluid, $\rho_{\mathrm{L}}$ the density of the fluid, $\mathbf{D}$ the symmetric part of the velocity gradient tensor and $\mathbf{U}_{i}$ and $\boldsymbol{\omega}_{i}$ are the linear and angular velocities of the $i$ th particle. The above equations are solved using the initial condition, $\left.u\right|_{t=0}=u_{0}$, where $u_{0}$ is the known initial value of the velocity.

The linear velocity $\mathbf{U}_{i}$ and the angular velocity $\boldsymbol{\omega}_{i}$ of the $i$ th particle are governed by the equations

$m_{i} \frac{\mathrm{d} \mathbf{U}_{i}}{\mathrm{~d} t}=\mathbf{F}_{i}+\mathbf{F}_{\mathrm{E}, i}+\mathbf{F}_{\mathrm{g}}$
$I_{i} \frac{\mathrm{d} \boldsymbol{\omega}_{i}}{\mathrm{~d} t}=\mathbf{T}_{i}$

$\left.\mathbf{U}_{i}\right|_{t=0}=\mathbf{U}_{i, 0}$

$\left.\boldsymbol{\omega}_{i}\right|_{t=0}=\boldsymbol{\omega}_{i, 0}$

where $m_{i}$ and $I_{i}$ are the mass and moment of inertia of the $i$ th particle, $\mathbf{F}_{i}$ and $\mathbf{T}_{i}$ are the hydrodynamic force and torque acting on the $i$ th particle and $\mathbf{F}_{\mathrm{E}, i}=\mathbf{F}_{\mathrm{DEP}, i}+\mathbf{F}_{\mathrm{D}, i}$ is the electrostatic force acting on the $i$ th particle $\left(\mathbf{F}_{\mathrm{DEP}, i}\right.$ being the dielectrophoretic force and $\mathbf{F}_{\mathrm{D}, i}$ the electrostatic particle-particle interaction force, estimated in this paper by the point dipole approximation) and $\mathbf{F}_{\mathrm{g}}$ is the force of gravity on the particle (see refs. [11,12] for more details). In this work, the point dipole approximation is used to compute both the dielectrophoretic force and the electrostatic particle-particle interactions, which leads to accurate results when the size of the particles is smaller than the scale of non-uniformity of the electric field. If this is not the case, an alternative numerical scheme such as that based on the Maxwell stress tensor and used in refs. $[13,14]$ is needed. Also, as the size of the particles becomes very small (nanoscale), Brownian motion may need to be accounted for [15]. In this paper, the physical set-up is such that these complications need not be considered. We also assume that the particles are spherical, and therefore we do not need to keep track of their orientations. The particle positions are obtained from the equations

$\frac{\mathrm{d} \mathbf{X}_{i}}{\mathrm{~d} t}=\mathbf{U}_{i}$
$\left.\mathbf{X}_{i}\right|_{t=0}=\mathbf{X}_{i, 0}$

where $\mathbf{X}_{i, 0}$ is the position of the $i$ th particle at time $t=0$. Here, we assume that all particles have the same density $\rho_{\mathrm{p}}$, and since they have the same radius, they also have the same mass, $m$.

In order to calculate the electric field $\mathbf{E}$, we first solve the electric potential problem $\nabla^{2} \phi=0$, subjected to prescribed boundary conditions, and then calculate $\mathbf{E}=-\nabla \phi$.

\subsection{Results of numerical simulations}

A preliminary investigation of the system indicates that negative (rather than positive) dielectrophoresis takes place and therefore we simulate a situation where the $\operatorname{sign}$ of $\operatorname{Re}(\beta)$ is negative. The computational domain used for the simulation is only a fraction of the experimental device, as shown in Fig. 1, to which periodic boundary conditions are applied in the $z$-direction to recover the experimental device. The bottom $y-z$ plane of the domain contains aligned castellated electrodes.

For the simulations the value of $\beta$ was set to -0.297 , while the radius of the particles used was $10 \mu \mathrm{m}$. In simulations we used larger sized particles than in the experiments in order to account for the fact that the HAP particles agglomerate into larger sized particles as soon as they are mixed with water. The density of the particles was $3000 \mathrm{~kg} / \mathrm{m}^{3}$. The density of the suspending liquid was $1000 \mathrm{~kg} / \mathrm{m}^{3}$ and its viscosity was $0.001 \mathrm{~N} \mathrm{~s} / \mathrm{m}^{2}$. The electric field distribution in the plane of electrodes is shown in 


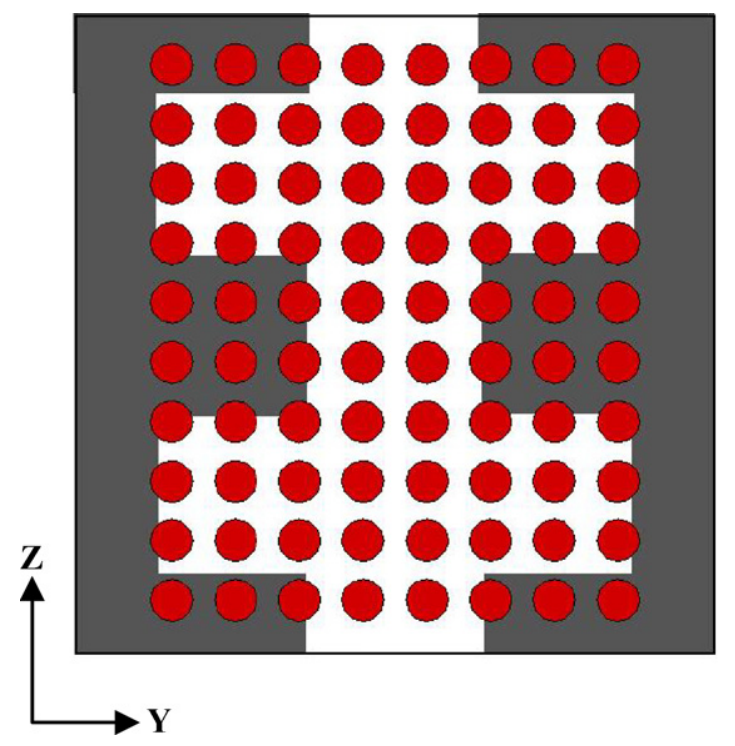

Fig. 1. Computational domain showing the electrodes as blackened areas, as well as the initial particle positions used in the numerical simulation.

Fig. 2 while Fig. 3 displays the dielectrophoretic force lines in the same plane. The latter predict that as the particles settle on the surface of the device due to the force of gravity, they will migrate to the areas of lowest electric field magnitude (i.e., the darker blue areas in Fig. 2). Such areas are located in the "wells" between the electrodes, as well as on the top and in the middle of the electrodes.

Eighty particles, each representing a cluster of HAP particles in the experiments, are initially arranged in a periodic fashion in the domain as shown in Fig. 1. Once the simulations are started the particles start falling due to gravity, while simultaneously moving to the regions of low electric field. The positions of the particles at time $t=1.0 \mathrm{~s}$ are shown in Fig. 4, which demonstrates that the particles have accumulated in the regions of low electric field.

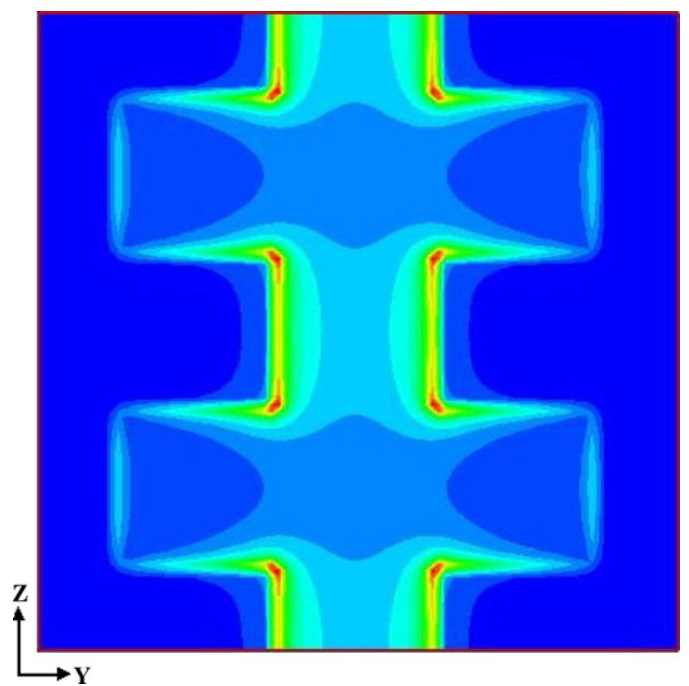

Fig. 2. Electric field distribution in the plane of the electrodes from the numerical simulation.

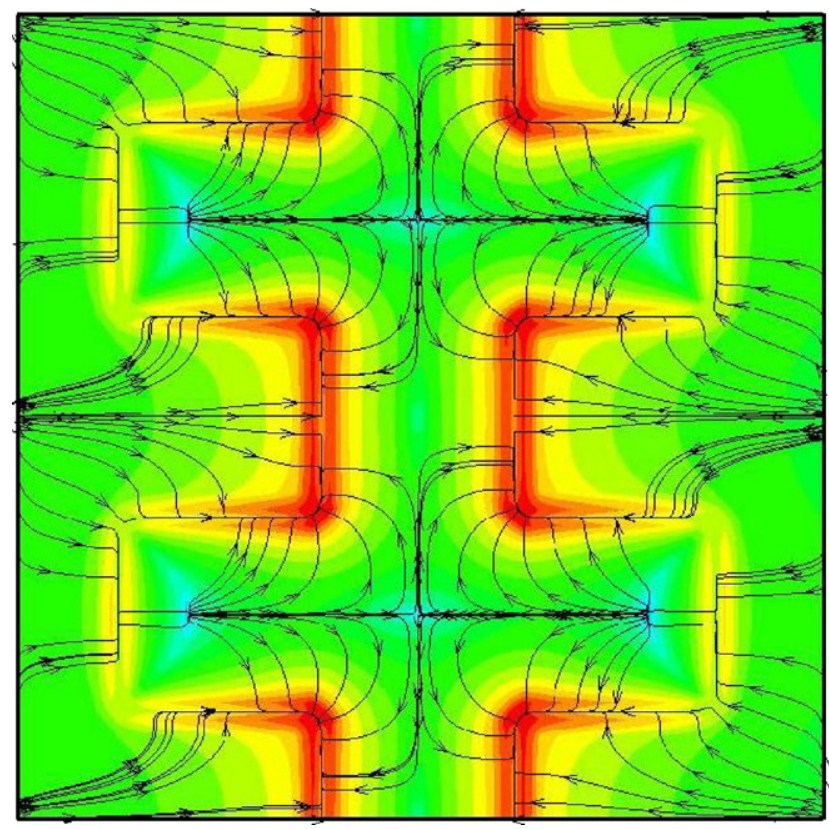

Fig. 3. Dielectrophoretic force lines in the plane of the electrodes from the numerical simulation. In case of negative dielectrophoresis, particles will move in the direction opposite to that of the arrows.

\section{Experiment}

\subsection{Microfluidic devic}

The device used in the experiments is the Microfluidic Platform for Manipulating Micro and Nanoscale Particles developed at NJIT, previously reported in refs. $[9,16]$ and used to study various clustering regimes of viable yeast cells [17]. The device is an integrated dual-microelectrode array chamber, which was designed and fabricated using standard microfabrication techniques. For the experiments reported in this paper,

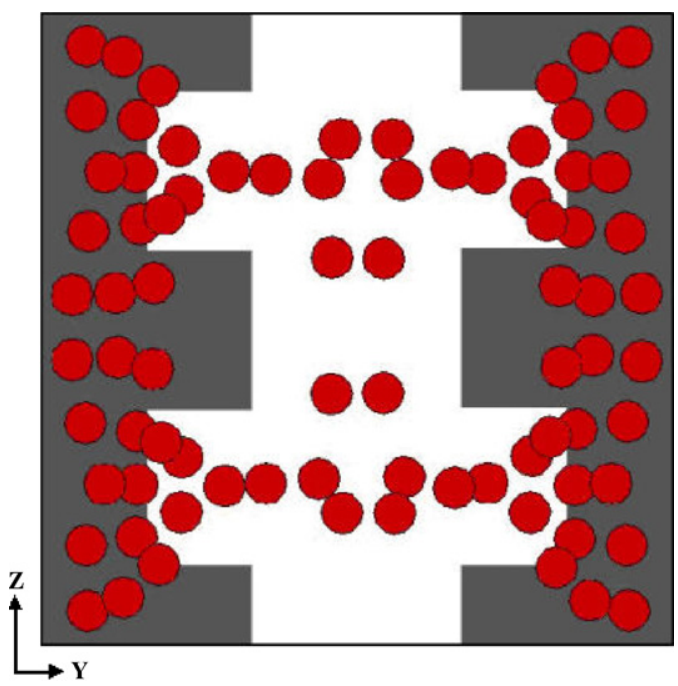

Fig. 4. Positions of the particles at time $t=1.0 \mathrm{~s}$ from the numerical simulation, showing streaks of particles aligned in the $z$-direction on top of the electrodes and bridges in the wells in between the electrodes. 


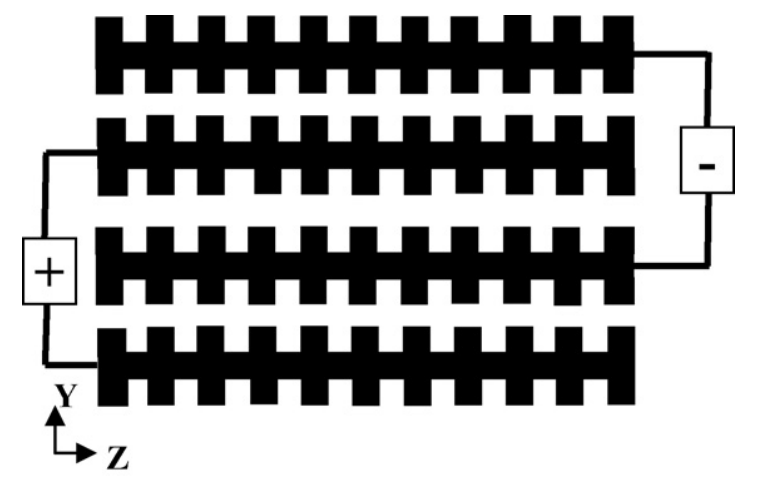

Fig. 5. Experimental electrode geometry: periodic, aligned, castellated bars of electrodes, represented by the blackened areas. The electrode width and spacing between the electrodes are both $100 \mu \mathrm{m}$.

we operated the device in the open-air and under static flow conditions.

The electrode geometry design used in the experiments described below is a periodic aligned, castellated bar geometry with a symmetrical electrode width and spacing between the electrodes of $100 \mu \mathrm{m}$ (see Fig. 5).

\subsection{Experimental procedure}

The experimental set-up is shown in Fig. 6. The liquid solution containing the HAP particles was pipetted onto the microfluidic device which was mounted on the stage of a Nikon Metallurgical MEC600 microscope. We applied a voltage to the electrodes by using a variable frequency ac signal generator (BK Precision Model 4010A). The applied voltage signal and resulting current were monitored with an oscilloscope and a digital voltmeter. The maximum applied voltage across the electrodes was $8 \mathrm{~V}$ ac rms. Considering that the distance between the electrodes was $100 \mu \mathrm{m}$, the electric field strength in the device was estimated to be $80 \mathrm{kV} / \mathrm{m}$. The motion of the particles was then observed and recorded using a Digital Color CCD camera mounted on the microscope and connected to a PC.
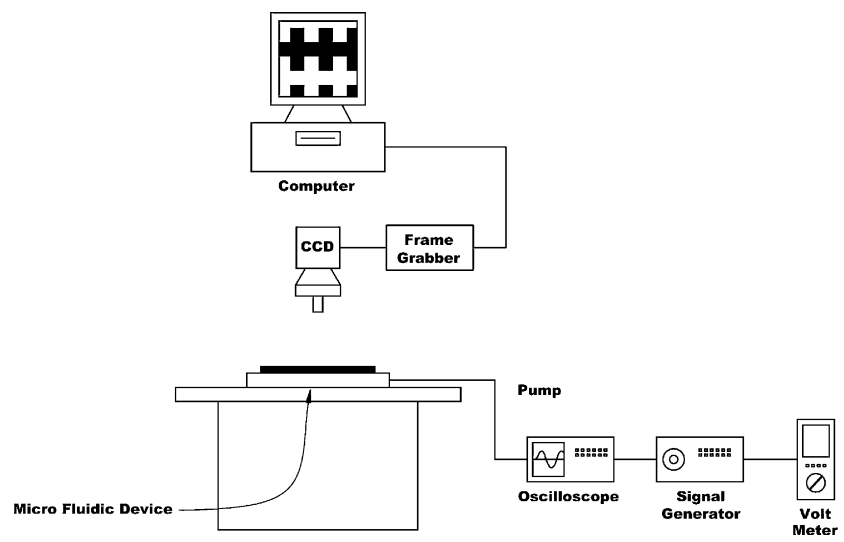

Fig. 6. Experimental set-up.

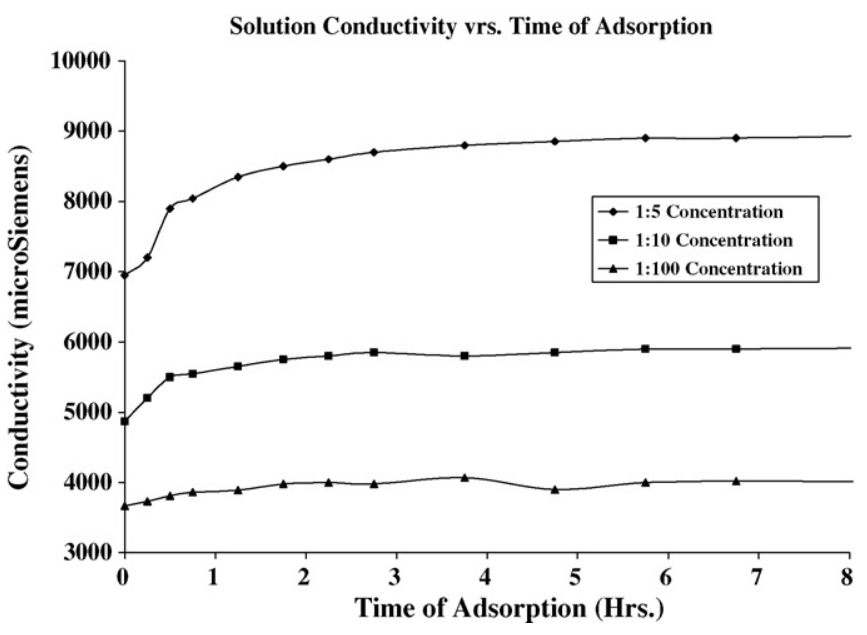

Fig. 7. HAP/lead nitrate/DI water solution conductivity as a function of time of adsorption.

\subsection{Preparation of the solution}

The contaminated water solution was prepared by diluting $1 \mathrm{~L}$ of $18 \mathrm{M} \Omega$ deionized laboratory grade water with $6 \mathrm{~g}$ of lead nitrate powder (Sigma-Aldrich) resulting in a $6 \mathrm{~g} / \mathrm{L} \mathrm{con-}$ centration of lead nitrate/DI water solution. A suspension of concentration 5:100 (ratio of volume fraction of HAP particles to that of the liquid) was then obtained by adding the HAP powder to the lead water solution and stirring for $24 \mathrm{~h}$ to allow total adsorption of the lead nitrate by the HAP. The mean diameter of the HAP powder was $1 \mu \mathrm{m}$. When added to water, the fine $1 \mu \mathrm{m}$ HAP particles tended to agglomerate (due to their high specific surface area), thus forming particle clusters of larger size.

Table 1

Electrical properties of the 5:100 suspension of lead adsorbed HAP powder and that of the fluid alone at various electric field frequencies

\begin{tabular}{lllll}
\hline Frequency & $\varepsilon_{\mathrm{s}}$ & $\sigma_{\mathrm{s}}$ & $\varepsilon_{\mathrm{c}}$ & $\sigma_{\mathrm{c}}$ \\
\hline $2.62 \mathrm{E}+04$ & $4.25 \mathrm{E}+04$ & $2.69 \mathrm{E}-03$ & $4.63 \mathrm{E}+04$ & $2.68 \mathrm{E}-03$ \\
$1.81 \mathrm{E}+04$ & $6.14 \mathrm{E}+04$ & $2.58 \mathrm{E}-03$ & $7.24 \mathrm{E}+04$ & $2.52 \mathrm{E}-03$ \\
$1.25 \mathrm{E}+04$ & $8.74 \mathrm{E}+04$ & $2.51 \mathrm{E}-03$ & $1.05 \mathrm{E}+05$ & $2.40 \mathrm{E}-03$ \\
$8.59 \mathrm{E}+03$ & $1.26 \mathrm{E}+05$ & $2.46 \mathrm{E}-03$ & $1.48 \mathrm{E}+05$ & $2.31 \mathrm{E}-03$ \\
$5.92 \mathrm{E}+03$ & $1.85 \mathrm{E}+05$ & $2.42 \mathrm{E}-03$ & $2.05 \mathrm{E}+05$ & $2.26 \mathrm{E}-03$ \\
$4.09 \mathrm{E}+03$ & $2.77 \mathrm{E}+05$ & $2.37 \mathrm{E}-03$ & $2.85 \mathrm{E}+05$ & $2.23 \mathrm{E}-03$ \\
$2.82 \mathrm{E}+03$ & $4.19 \mathrm{E}+05$ & $2.29 \mathrm{E}-03$ & $4.04 \mathrm{E}+05$ & $2.21 \mathrm{E}-03$ \\
$1.94 \mathrm{E}+03$ & $6.31 \mathrm{E}+05$ & $2.18 \mathrm{E}-03$ & $5.86 \mathrm{E}+05$ & $2.18 \mathrm{E}-03$ \\
$1.34 \mathrm{E}+03$ & $9.22 \mathrm{E}+05$ & $2.06 \mathrm{E}-03$ & $8.65 \mathrm{E}+05$ & $2.11 \mathrm{E}-03$ \\
$9.24 \mathrm{E}+02$ & $1.30 \mathrm{E}+06$ & $1.94 \mathrm{E}-03$ & $1.24 \mathrm{E}+06$ & $2.02 \mathrm{E}-03$ \\
$6.37 \mathrm{E}+02$ & $1.75 \mathrm{E}+06$ & $1.82 \mathrm{E}-03$ & $1.75 \mathrm{E}+06$ & $1.96 \mathrm{E}-03$ \\
$4.40 \mathrm{E}+02$ & $2.30 \mathrm{E}+06$ & $1.76 \mathrm{E}-03$ & $2.45 \mathrm{E}+06$ & $1.89 \mathrm{E}-03$ \\
$3.03 \mathrm{E}+02$ & $3.05 \mathrm{E}+06$ & $1.71 \mathrm{E}-03$ & $3.32 \mathrm{E}+06$ & $1.84 \mathrm{E}-03$ \\
$2.09 \mathrm{E}+02$ & $4.05 \mathrm{E}+06$ & $1.67 \mathrm{E}-03$ & $4.44 \mathrm{E}+06$ & $1.81 \mathrm{E}-03$ \\
$1.44 \mathrm{E}+02$ & $5.47 \mathrm{E}+06$ & $1.64 \mathrm{E}-03$ & $6.03 \mathrm{E}+06$ & $1.79 \mathrm{E}-03$ \\
$9.94 \mathrm{E}+01$ & $7.61 \mathrm{E}+06$ & $1.60 \mathrm{E}-03$ & $8.52 \mathrm{E}+06$ & $1.79 \mathrm{E}-03$ \\
$6.86 \mathrm{E}+01$ & $1.08 \mathrm{E}+07$ & $1.57 \mathrm{E}-03$ & $1.23 \mathrm{E}+07$ & $1.80 \mathrm{E}-03$ \\
\hline
\end{tabular}

The subscript 's' refers to the suspension while the subscript 'c'refers to the continuous phase (liquid). Variables shown are the permittivity $\varepsilon^{\prime}$ and the electric conductivity $\sigma^{\prime}$. Conductivity values are given in $\mathrm{S} / \mathrm{cm}$ and permittivity values have been non-dimensionalized with the permittivity of the vacuum. 
A study was performed to determine the dc conductivity of the solution as a function of time of adsorption for three different concentrations of HAP powder in the lead nitrate/DI water. This was performed using a dc meter to measure conductivity. Fig. 7 shows that the initial conductivity depends on the concentration of HAP particles in the fluid and that the conductivity of the solution increases with time of adsorption. Notice that the rate of change is larger during the first hour of adsorption due to a significant ion exchange during dissolution.

Hereafter, the solution studied is the 5:100 suspension previously described. We performed measurements of conductivity and permittivity of both the suspension and the suspending fluid, that is deionized water, by means of a broadband dielectric spectrometer (BDS)-80 (Novocontrol, Gmbh) with temperature control using a liquid sample cell BDS 1308 (specifically for water based solutions). The measurements were carried out in a spatially uniform low electric field $(\sim 4 \mathrm{~V} / \mathrm{mm})$ for a range of frequencies from 0.5 to $10,000 \mathrm{~Hz}$. Table 1 shows the results of the measurement for the range of frequencies in which the experiments were conducted.

\subsection{Experimental results}

Table 1 reports the values of conductivity and permittivity obtained from our BDS measurements. In the range of frequencies used in the experiments, we are in the regime of negative dielectrophoresis, in which case particles are collected in contact less traps without getting attached to the electrode or wall edges. This may offer an advantage in the subsequent removal of particles, especially if combined with traveling wave dielectrophoresis which has the potential to carry particles along the channel axis without the need of pumping the fluid itself $[18,19]$.

In this paper, negative dielectrophoresis should make particles migrate toward areas of low magnitude of the electric field, i.e., the darker blue areas in Fig. 2.

Fig. 8 shows the initial, quasi-homogeneous distribution of the particles immediately after being pipetted onto the device. Shortly after, the particles begin to fall toward the device surface due to the action of gravity. As they fall, they experience

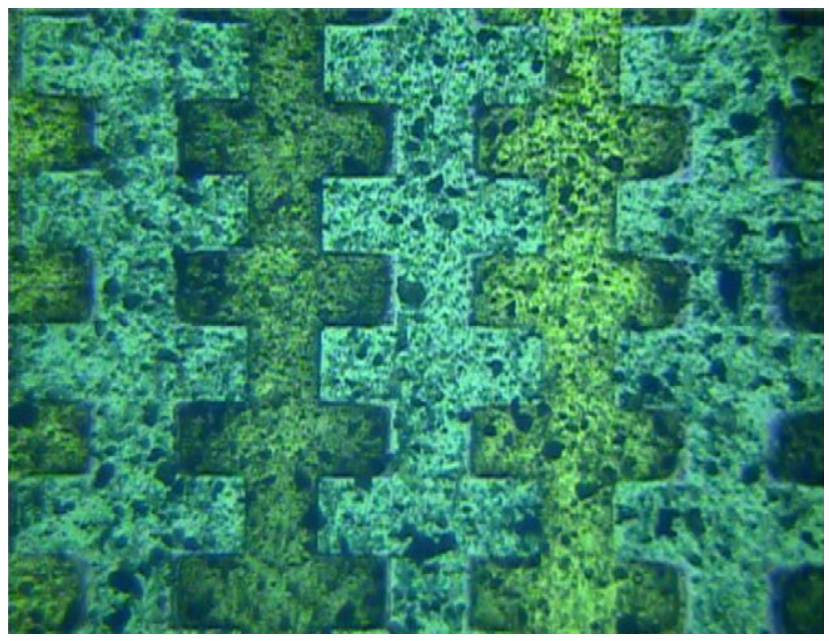

Fig. 8. Initial distribution of particles in the experiment.

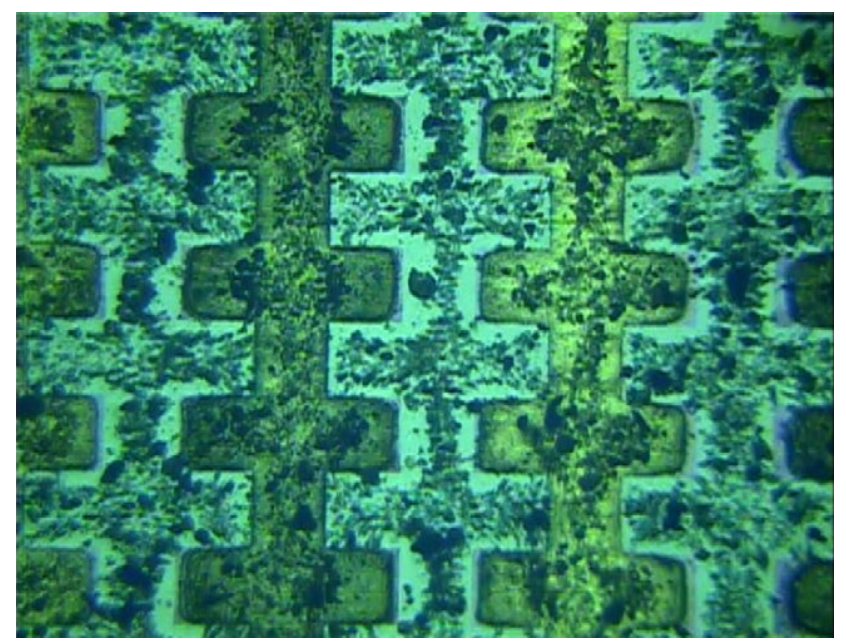

Fig. 9. Particle distribution in the experiment $5 \mathrm{~s}$ after voltage is applied to the electrodes.

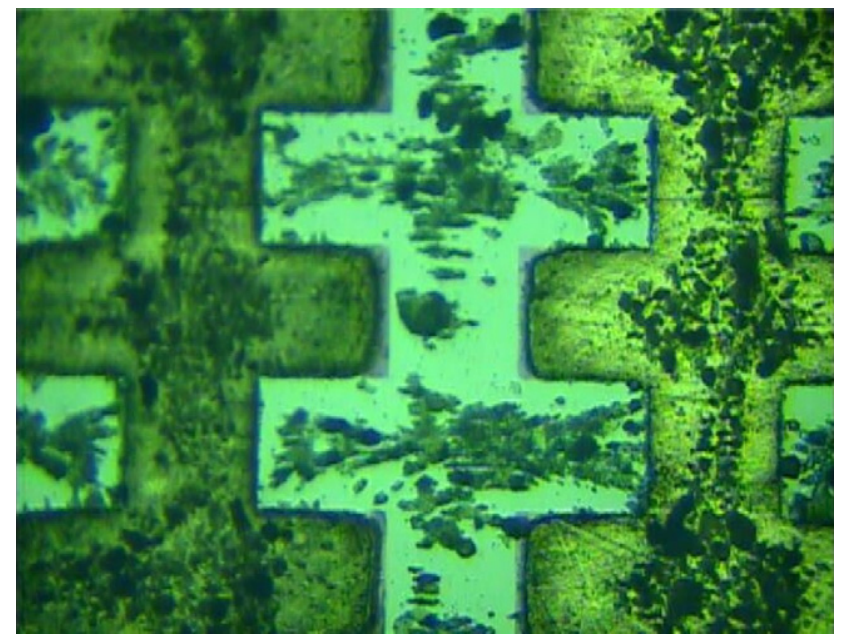

Fig. 10. Magnified view of particle distribution $5 \mathrm{~s}$ after voltage is applied to the electrodes.

the DEP force and are pushed to the regions of lowest electric field magnitude. Fig. 9 displays the particle distribution after $5 \mathrm{~s}$ of settling while Fig. 10 shows a magnified view of particle patterns. As can be seen from the images, the particles migrate under the influence of the DEP force to the areas of lowest electric field magnitude, thus forming elongated streaks on top of the electrodes in the $z$-direction and perpendicular patterns in the $y$-direction in the wells in between electrodes, as predicted by the numerical simulations.

\section{Conclusion}

We have demonstrated that dielectrophoresis can be used to manipulate and immobilize hydroxyapatite particles in water after they have adsorbed the lead originally present in the solution. This results in localized areas with a high concentration of particles, rendering the rest of the solution volume nearly free of contaminated particles and therefore clean. These findings offer much promise for the design of novel heavy metal waste water filtration devices, particularly for efficiently collecting and 
removing particles suspended in real-world gel state liquids. The results and findings of this low concentration study will be used to aid in understanding the collection and filtration of particles in highly concentrated suspensions.

\section{Acknowledgements}

The authors are grateful to the New Jersey Commission on Science and Technology for their financial support through the Center for Micro-Flow Control under Grant \#01-2042-007-25 to the office of Naval Research under contract \#N00014-04-0389 and to the W.M. Keck Foundation for their grant to establish the NJIT W.M. Keck laboratory. The authors would also like to thank the European Commission under the Asia-Link Programme (Number: CN/ASIA-LINK/010 (94-556)) for supporting this rerearch. We are grateful to George Barnes for his technical support.

\section{References}

[1] S. Bailliez, A. Nzihou, E. Bèche, G. Flamant, Removal of lead $(\mathrm{Pb})$ by hydroxyapatite sorbents, Trans. IChemE Part B: Process Saf. Environ. Prot. 82 (B2) (2004) 1-6.

[2] B. Bournonville, A. Nzihou, P. Sharrock, P. Piantone, Mineral species formed by treating fly ash with phosphoric acid, J. Hazard. Mater. B116 (2004) 65-74.

[3] S. Iretskaya, A. Nzihou, C. Zahraoui, P. Sharrock, Metal leaching from fly ash before and after chemical and thermal treatment, Environ. Prog. 18 (2) (1999) 144-148.

[4] H.A. Pohl, Dielectrophoresis, Cambridge University Press, Cambridge, 1978.

[5] P.R.C. Gascoyne, J. Noshari, F.F. Becker, R. Pethig, Use of dielectrophoretic collection spectra for characterizing differences between normal and cancerous cells, IEEE Trans. Ind. Appl. 30 (1994) 829-834.
[6] N.G. Green, H. Morgan, Dielectrophoresis of submicrometer latex spheres. 1. Experimental results, J. Phys. Chem. B 103 (1999) 41-50.

[7] M.P. Hughes, H. Morgan, Dielectrophoretic trapping of a single submicrometre scale bioparticle, J. Phys. D: Appl. Phys. 31 (1998) 22052210.

[8] M.P. Hughes, H. Morgan, Measurement of bacterial flagellar thrust by negative dielectrophoresis, Biotechnol. Prog. 15 (1999) 245-249.

[9] J. Kadaksham, J. Batton, P. Singh, N. Aubry, Microfluidic platform for manipulating micro and nanoscale particles, in: Proceedings of IMECE2003 ASME International Mechanical Engineering Congress and RD\&D Expo, Washington, DC, November 15-21, 2003, p. 41582.

[10] P. Singh, D.D. Joseph, T.I. Hesla, R.T. Glowinski, W. Pan, A distributed Lagrange multiplier/fictitious domain method for particulate flows, J. NonNewton. Fluid Mech. 91 (2000) 165-188.

[11] J. Kadaksham, P. Singh, N. Aubry, Dynamics of electrorheological suspensions subjected to spatially nonuniform electric fields, J. Fluids Eng. 120 (2004) 170-179.

[12] J. Kadaksham, P. Singh, N. Aubry, Manipulation of particles using dielectrophoresis, Mech. Res. Commun. 33 (2006) 108-122.

[13] P. Singh, N. Aubry, Trapping force on a finite sized particle in a dielectrophoretic cage, Phys. Rev. E 72 (2005) 016602.

[14] P. Singh, N. Aubry, Control of electrostatic particle-particle interactions in dielectrophoresis, Euro Phys. Lett., in press.

[15] J. Kadaksham, P. Singh, N. Aubry, Dielectrophoresis of nanoparticles, Electrophoresis 25 (2004) 3625-3632.

[16] J. Kadaksham, J. Batton, P. Singh, N. Golubovic-Liakopoulos, N. Aubry, Dielectrophoretic manipulation of micro- and nanoscale particles in microchannels, in: Nanotechnology World Forum, Marlborough, MA, June 23-25, 2003.

[17] J. Kadaksham, P. Singh, N. Aubry, Dielectrophoresis induced clustering regimes of viable yeast cells, Electrophoresis 26 (2005) 3738-3744.

[18] N. Aubry, P. Singh, Influence of particle-particle interactions and particle rotational motions in traveling wave dielectrophoresis, Electrophoresis 27 (3) (2006) 703-715.

[19] C. Nudurupati, P. Singh, N. Aubry, Electrohydrodynamics of yeast cells in traveling electric fields, submitted for publication. 